\title{
Türkiye'de İnvazif Streptokok Enfeksiyonlarının Epidemiyolojisi, Klinik ve Mikrobiyolojik Özellikleri, 2010-2011
}

\section{Epidemiology, Clinical and Microbiological Characteristics of Invasive Streptococcal Infections in Turkey, 2010-2011}

Aynur Eren TOPKAYA ${ }^{1}$, Ahmet BALIKCl ${ }^{2}$, Faruk AYDIN ${ }^{3}$, Gülşen HASÇELiK ${ }^{4}$, Tuba KAYMAN ${ }^{5}$, Recep KESLi ${ }^{6}$, Şöhret AYDEMIR ${ }^{7}$, Işın AKYAR ${ }^{8}$, Aslı GÖKALP ${ }^{9}$, Günnur DÜNDAR ${ }^{10}$, Nezahat GÜRLER ${ }^{11}$, Duygu PERÇiN ${ }^{12}$, Duygu FINDIK ${ }^{13}$, Haluk AVUNDUK ${ }^{14}$, Banu BAYRAKTAR ${ }^{15}$

\footnotetext{
${ }^{1}$ Namık Kemal Üniversitesi Tıp Fakültesi, Tıbbi Mikrobiyoloji Anabilim Dalı, Tekirdağ.

${ }^{1}$ Namik Kemal University Faculty of Medicine, Department of Medical Microbiology, Tekirdağ, Turkey.

${ }^{2}$ Süreyyapaşa Göğüs Hastalıkları Eğitim ve Araştırma Hastanesi, Mikrobiyoloji Laboratuvarı, İstanbul.

${ }^{2}$ Sureyyapasa Chest Diseases Education and Research Hospital, Microbiology Laboratory, Istanbul, Turkey.

${ }^{3}$ Karadeniz Teknik Üniversitesi Tıp Fakültesi, Tıbbi Mikrobiyoloji Anabilim Dalı, Trabzon.

${ }^{3}$ Karadeniz Technical University Faculty of Medicine, Department of Medical Microbiology, Trabzon, Turkey.

${ }^{4}$ Hacettepe Üniversitesi Tıp Fakültesi, Tıbbi Mikrobiyoloji Anabilim Dalı, Ankara.

${ }^{4}$ Hacettepe University Faculty of Medicine, Department of Medical Microbiology, Ankara, Turkey.

${ }^{5}$ Erciyes Üniversitesi Tıp Fakültesi, Tıbbi Mikrobiyoloji Anabilim Dalı, Kayseri.

5 Erciyes University Faculty of Medicine, Department of Medical Microbiology, Kayseri, Turkey.

${ }^{6}$ Konya Eğitim ve Araştırma Hastanesi, Mikrobiyoloji Laboratuvarı, Konya.

${ }^{6}$ Konya Education and Research Hospital, Microbiology Laboratory, Konya, Turkey.

${ }^{7}$ Ege Üniversitesi Tıp Fakültesi, Tıbbi Mikrobiyoloji Anabilim Dalı, İzmir.

${ }^{7}$ Ege University Faculty of Medicine, Department of Medical Microbiology, Izmir, Turkey.

${ }^{8}$ Acıbadem Üniversitesi Tıp Fakültesi, Tıbbi Mikrobiyoloji Anabilim Dalı, İstanbul.

${ }^{8}$ Acibadem University Faculty of Medicine, Department of Medical Microbiology, Istanbul, Turkey.

${ }^{9}$ Ahenk Laboratuvarları, İstanbul.

${ }^{9}$ Ahenk Laboratories, Istanbul, Turkey.

${ }^{10}$ Centro Laboratuvarları, İstanbul.

${ }^{10}$ Centro Laboratories, Istanbul, Turkey.

11 istanbul Üniversitesi İstanbul Tıp Fakültesi, Tıbbi Mikrobiyoloji Anabilim Dalı, İstanbul.

${ }^{11}$ Istanbul University Istanbul Faculty of Medicine, Department of Medical Microbiology, Istanbul, Turkey.

${ }^{12}$ Kayseri Eğitim ve Araştırma Hastanesi, Mikrobiyoloji Laboratuvarı, Kayseri.

12 Kayseri Education and Research Hospital, Microbiology Laboratory, Kayseri, Turkey.

13 Selçuk Üniversitesi Tıp Fakültesi, Tıbbi Mikrobiyoloji Anabilim Dalı, Konya.

13 Selcuk University Medical School, Department of Medical Microbiology, Konya, Turkey.

${ }^{14}$ Sivas Devlet Hastanesi, Mikrobiyoloji Laboratuvarı, Sivas.

14 Sivas State Hospital Microbiology Laboratory, Sivas, Turkey.

15 Şişli Etfal Eğitim ve Araştırma Hastanesi, Mikrobiyoloji Laboratuvarı, İstanbul.

15 Sisli Etfal Education and Research Hospital, Microbiology Laboratory, Istanbul, Turkey.
}

Geliş Tarihi (Received): 24.06.2013 • Kabul Ediliş Tarihi (Accepted): 11.12.2013

Iletişim (Correspondence): Yrd. Doç. Dr. Ahmet Balıkcı, İstanbul Süreyyapaşa Göğüs Hastalıkları Eğitim Araştırma Hastanesi, Tıbbi Mikrobiyoloji, ístanbul, Türkiye. Tel (Phone): +90 536227 9283, E-posta (E-mail): balikciahmet@gmail.com 
Türkiye'de İnvazif Streptokok Enfeksiyonlarının Epidemiyolojisi,

Klinik ve Mikrobiyolojik Özellikleri, 2010-2011

\section{ÖZET}

Bu çalışmada, ülkemizdeki invazif A grubu streptokok (AGS) enfeksiyonlarının epidemiyolojik ve mikrobiyolojik özelliklerinin belirlenmesi ve bu hastalıkların önlenmesinde uygulanacak olan ulusal stratejilere veri sağlanması amacıyla bir yıllık aktif sürveyans yapılması planlanmıştır. Çalışmaya, Türkiye'nin 12 farklı bölgesinden (İstanbul; Doğu ve Batı Marmara; Doğu ve Batı Karadeniz; Ege; Akdeniz; Batı, Orta, Kuzeydoğu, Ortadoğu ve Güneydoğu Anadolu) toplam 46 klinik mikrobiyoloji laboratuvarı katılmıştır. Katılımcı merkezlerde, Haziran 2010-Haziran 2011 tarihleri arasında steril vücut bölgelerinden (kan, beyin omurilik sıvısı, eklem, plevra, periton, perikard sıvıları) izole edilen AGS'ler, doğrulama ve ileri çalışmalar için Maltepe Üniversitesi Tıp Fakültesi, Tıbbi Mikrobiyoloji Anabilim Dalı Laboratuvarına gönderilmiştir. Bakterilerin tanımlanması konvansiyonel yöntemlerle yapılmış; serotiplendirme için opasite faktörü (OF) ve T protein tipleri araştııımış, genotiplendirme için AGS lizatı hazırlama, emm geni amplifikasyonu ve dizilenmesi, "Centers for Disease Control and Prevention" protokolüne göre uygulanmıştır. Çalışma dönemi içinde katılımcı merkezlerin 15'inden, 65 invazif AGS suşu izole edilmiştir. İnvazif AGS izolasyon oranının bölgesel farkılıklar gösterdiği belirlenmiş, en yüksek izolasyonun Doğu Karadeniz (Trabzon; $n=19)$ bölgesinde olduğu, bunu i̇stanbul $(n=17)$ ve Batı Anadolu (Ankara, Konya; $n=14)$ bölgelerinin izlediği görülmüştür. İnvazif AGS enfeksiyonu tanısı konulan hastaların 33'ü kadın, 32'si erkek olup, yaş aralığı 0-89 yıl arasındadır. AGS suşlarının en fazla yumuşak doku $(n=18)$, apse $(n=10)$, steril vücut sıvısı $(n=8)$ ve kan $(n=7)$ örneklerinden izole edildiği gözlenmiştir. Serotiplendirme sonucunda $36(\% 55)$ izolatın OF pozitif olduğu saptanmış; en sık saptanan T protein tipleri poligrup T $(n=20)$ ve $U(n=14)$ olmuş, bunları $B(n=5), X(n=3)$ ve $Y(n=2)$ izlemiştir. Yirmi iki izolatta T proteini tespit edilememiştir. Genotiplendirme sonucunda izolatların 17 farklı emm tipine sahip olduğu saptanmış; en sık rastlanan tipler; emm1 $(n=13), e m m 4(n=6), e m m 6(n=6), e m m 12(n=6), e m m 24(n=4), e m m 14(n=3)$ ve emm28 $(n=3)$ olarak belirlenmiş, dokuz suş dizileme ile tiplendirilememiştir. İzolatların emm tipleri ile serotipleri arasındaki korelasyon \%58 olarak bulunmuştur. Kullanımdaki 26 değerli aşının invazif AGS suşlarının \%70.5'ini kapsadığı tespit edilmiştir. Sonuç olarak bu çalışmayla Türkiye'de invaziv AGS enfeksiyonlarının epidemiyolojik ve mikrobiyolojik özellikleriyle ilgili ilk veriler elde edilmiştir. İnvazif AGS enfeksiyon sıklığının ülkemizde düşük olduğu, 26 değerli ASG aşııının aşı programına dahil edilmesinin ülkemiz için şu anda acil halk sağlığı sorunu olmadığı ve eğer ülkemizde kullanılacaksa aşıya emm4 ve emm24 tiplerinin de eklenmesi gerektiği ortaya çıkmıştır.

Anahtar sözcükler: Grup A streptokok; invazif enfeksiyon; epidemiyoloji; emm geni; dizileme; serotiplendirme.

\section{ABSTRACT}

A one-year active surveillance study was conducted to investigate the epidemiological and microbiological characteristics of invasive group A streptococci (GAS) infections in Turkey and to provide data for the establishment of national preventive strategies related to invasive GAS infections. A total of 46 clinical microbiology laboratories from 12 different regions of Turkey (Istanbul; Eastern and Western Marmara; Eastern and Western Blacksea; Aegean; Mediterranean; Western, Central, Northeastern, Middle-eastern and Southeastern Anatolia) participated in the study. Accordingly, GAS strains isolated from sterile body sites (blood, cerebrospinal, synovial, pleural, peritoneal, pericardial fluids) in the study centers between June 2010-June 2011, were sent to Maltepe University Hospital Clinical Microbiology Laboratory for microbiological confirmation and further analysis. The isolates were identified by conventional methods, and for serotyping, opacity factor (OF) and T protein types were investigated. For genotyping GAS lysate preparation, emm gene amplification and sequencing were performed by using the protocols recommended by Centers for Disease Control and Prevention. A total of 65 invasive GAS strains were isolated in 15 of the participant centers, during the study period. The rate of invasive GAS 
isolation exhibited regional variation, with the highest rates in the Eastern Blacksea (Trabzon, $n=19$ ), followed by Istanbul $(n=17)$ and Western Anatolia (Ankara, Konya, $n=14)$. Of the patients with invasive GAS infection 33 were female, 32 were male, with the age range of 0-89 years. GAS strains were most commonly isolated from soft tissue specimens $(n=18)$, followed by abscess material $(n=10)$, sterile body fluids $(n=8)$ and blood $(n=7)$ samples. Serotyping revealed that $55 \%(36 / 65)$ of the strains were OF positive, and the majority of T protein was polygroup $T(n=20)$, followed by $U(n=14), B(n=5), X(n=$ 3 ) and $Y(n=2)$. T protein was not detected in 22 isolates. The strains were found to have 17 different emm types; emm1 $(n=13)$, emm4 $(n=6)$, emm6 $(n=6)$, emm12 $(n=6), \operatorname{emm} 24(n=4), \operatorname{emm} 14(n=3)$ and emm28 $(n=3)$. Nine of the strains could not be typed by sequencing. The correlation between emm typing and serotyping was detected as $58 \%$. It was observed that 26 -valent vaccines included $70.5 \%$ of the invasive GAS strains included in this study. Our study provided initial data concerning the epidemiological properties of invasive GAS infections and characterization of GAS strains in Turkey. The incidence of invasive GAS infections is low in our country. Although immunization programme by 26-valent GAS vaccine is not currently an urgent public health issue for our country, the results of this study indicated that emm types 4 and 24 should better be included in such a vaccine to be used in Turkey. Additionally, since epidemiological features of GAS infections and the microbiological characteristics of the strains can vary by time, for the diagnosis of invasive streptococcal infections and to take the necessary preventive measures, epidemiological studies should be conducted repeatedly.

Key words: Group A streptococci; invasive infection; epidemiology; emm gene; sequencing; serotyping.

\section{Gíriş}

Önemli bir insan patojeni olan Streptococcus pyogenes (A grubu streptokok; AGS) tarafından oluşturulan impetigo, farenjit, kızıl, sepsis, nekrotizan fasiit, streptokokal toksik şok sendromu (STSS) gibi akut enfeksiyonlar ve bunların süpüratif olmayan sekelleri (akut romatizmal ateş, akut glomerulonefrit) halen tüm dünyada ciddi bir halk sağlı̆̆ı problemidir ${ }^{1}$. AGS'lerin sebep olduğu invazif hastalıkların sıkığı 1980'li yılların ortasından beri tüm dünyada artmaktadır. Bu artışın nedeni tam olarak anlaşılamamakla birlikte, dikkatler AGS'ların epidemiyolojik ve mikrobiyolojik özelliklerindeki değişikliklere odaklanmıştır. Son çalışmalarda, gelişmiş ülkelerde invazif enfeksiyonların oranı \%2.53.5 iken, mortalite oranı \%7-15 olarak bildirilmiştir ${ }^{2-5}$. Invazif enfeksiyonlar ve mortalite oranları karşılaştııılıı̆ında, gelişmekte olan ülkelerin oranlarının gelişmiş ülkelere oranla anlamlı derecede yüksek olduğu görülmektedir. Gelişmekte olan ülkelere ait az sayıdaki epidemiyolojik ve mikrobiyolojik verilere göre, ölüm oranı \%95'e varan invazif hastalıklar saptanmıştır. Türkiye'de de diğer gelişmekte olan ülkelerde olduğu gibi, AGS enfeksiyonlarının klinik, epidemiyolojik ve mikrobiyolojik özellikleriyle ilgili çalışmalar yetersizdir.

M proteini AGS'lerde temel virülans faktörüdür. Fagositoz ve opsonizasyondan bakteriyi korur. Bu proteinlere karşı üretilen nötralize edici antikorlar AGS'ye karşı bağışıklıktan sorumludur ${ }^{6}$. M proteinine göre, $1980^{\prime}$ li yıllara kadar yaklaşık 80 antijenik serotip tanımlanmış; sonraki yıllarda invazif AGS oranlarının artmasıyla birlikte, bazı suşların $\mathrm{M}$ antiserumlarıyla tanımlanamadığı anlaşılmışır. Daha sonra M protenini kodlayan emm geni belirlenmiş ve antiserumlarla serotiplemesi yapılamayan kökenlerin genotipleme ile 
M tipi saptanmaya çalışılmıştır. Bundan sonra bu konudaki terminoloji de değişmiş ve M protein yapısı M-antiserumlar tarafından tespit edildi ise "M serotip"; 5' dizileme ile tespit edildiyse "emm tipi" olarak tanımlanmıştır. Emm türlerinin sayısı 2002 yılında altı streptokok referans laboratuvarının ortak çabalarıyla $124^{\prime}$ e ulaşmıştır ${ }^{7}$. Emm tipleme ve M serotipleme çalışmaları AGS'lerin klinik görünümü ile $M$ tipi arasındaki korelasyonun anlaşılmasını sağlamıştır. Hücre duvarındaki T proteini ve opasite faktörü (OF), tıpkı M proteini gibi AGS'lerde önemli bir epidemiyolojik belirteçtir. Belirli bazı M serotiplerinin, belirli T proteinleriyle birlikte bulunduğu ve yine bazı M serotiplerinin OF üretirken bazılarının üretmediği saptanmıştır ${ }^{8}$.

İnvazif hastalığa neden M serotiplerinin dağılımı, coğrafi bölgelere ve hatta aynı bölgede yıllara göre farklılık göstermektedir. Amerika Birleşik Devletleri (ABD)'nde,1995-1999 yılları arasında, genellikle tanımlanan invazif serotipler, sıklık sırasına göre M1, M28, M12, M3 ve M11 iken, 2000-2004 yılları arasında bu sıralama M1, M3 ve M12 şeklinde değişmiştir ${ }^{3}$.

Gelişmiş ülkelerde, epidemiyolojik çalışmalardan elde edilen verilere göre üretilen aşılardan başarılı sonuçlar elde edilmiş ve özellikle 6-26 değerli aşıların yüksek immün yanıt oluşturdukları gösterilmiştir. Bu ülkelerde yapılan çok merkezli çalışmalar, aşı serotiplerinin sıklığını ve aşı kullanıldıktan sonraki invazif hastalıkların prevalansını göstermiştir. $A B D$ 'de CDC ve Avrupa Birliğinde Strep-Euro çalışmalarıyla, aşı serotipleriyle AGS'lerin invazif serotipleri arasındaki korelasyon araştırılmıştır ${ }^{9}$. Türkiye'de ise invazif AGS enfeksiyonlarının epidemiyolojik ve mikrobiyolojik özelliklerini araştıran ve tüm bölgeleri kapsayan bir çalışma daha önce yapılmamıştır. Bu konudaki veriler, Doğu Karadeniz bölgesinden 22 invazif izolatın ve Marmara bölgesinden farenjit etkeni invazif olmayan 200 izolatın serotiplendiği az sayıdaki çalışma ile sınırlıdır ${ }^{10,11}$. Bu çalışmanın amacı, ülkemizin tüm coğrafi bölgelerini temsil etmek üzere belirli merkezler dahil edilerek invazif AGS enfeksiyonlarının aktif sürveyansını ve mikrobiyolojik özelliklerini belirlemektir. Böylece invazif streptokok hastalıklarının önlenmesiyle ilgili olarak, mevcut 26 değerli aşının etkinliğinin saptanmasına ve invazif AGS enfeksiyonları ile ilgili ulusal stratejilerin oluşturulmasına katkı sağlanacaktır.

\section{GEREÇ ve YÖNTEM}

Çalışmaya katılan merkezler, Türkiye İstatistik Enstitüsü tarafından belirlenen ekonomik, sosyal, kültürel ve coğrafi yönlerden benzer illerin, belirli bir nüfus büyüklüğü de dikkate alınarak gruplandırılması sonucu, alan bazlı örnekleme yöntemi ile 12 bölgeden seçildi (Tablo I). Örneklemede; Sağlık Bakanlığı Devlet Hastaneleri, Eğitim ve Araştırma Hastaneleri ve Üniversite Hastaneleri olmak üzere üç alt grup oluşturuldu. Bölgelerin her birinden, bu üç alt gruptan klinik mikrobiyoloji analizi yapmak için yetkili olan birer merkez rastgele belirlendi. Bir bölgede bu üç alt grup dışında başka bir kuruluş varsa doğrudan çalışmaya davet edildi. Davet kabul edilmediğinde ya da o bölgede yetkili 


\begin{tabular}{|llc|}
\hline \multicolumn{2}{|c|}{ Tablo I. Çalışmaya Katılan Merkezlerin Numaraları ve AGS Izolat Sayılarııın Dağııımı $(n=65)$} \\
\hline Merkez no. & Bölge & İzolat sayısı \\
\hline 1 & İstanbul & 17 \\
2 & Batı Marmara & - \\
3 & Ege & 6 \\
4 & Doğu Marmara & - \\
5 & Batı Anadolu & 14 \\
6 & Akdeniz & - \\
7 & Orta Anadolu & 8 \\
8 & Batı Karadeniz & - \\
9 & Doğu Karadeniz & 19 \\
10 & Kuzeydoğu Anadolu & 1 \\
11 & Ortadoğu Anadolu & - \\
12 & Güneydoğu Anadolu & - \\
\hline$(-):$ İnvazif AGS izolasyonu yapılmamıştır. & \\
\hline
\end{tabular}

klinik mikrobiyoloji laboratuvarı yokluğunda, o kontenjan boş bırakıldı. Çalışmaya 46 klinik mikrobiyoloji laboratuvarı katıldı ve çalışmanın epidemiyolojik kısmı bir yıl içinde tamamlandı. Invazif hastalık etkeni olarak izole edilen beta-hemolitik streptokokların tanımlaması, çalışmaya katılan merkezlerde standart mikrobiyolojik yöntemlerle yapıldı. Hastaların demografik ve klinik verileri için formlar oluşturuldu. Grup A beta-hemolitik streptokok olarak tanımlanan kökenler, Maltepe Üniversitesi Tıp Fakültesi, Tıbbi Mikrobiyoloji Anabilim Dalına serotip ve genotip tayini için gönderildi. Bu merkezde, referans yöntemlerle doğrulanan izolatlar sero- ve geno- tiplendirme çalışmalarına alındı. Klinik özellikler ve risk faktörleri ilgili anketler, çalışmaya katılan merkezlerin tümü tarafından tamamlanmadığı için bu konuda veri analizi yapılamadı.

\section{Olgu Tanımı ve Bakteri Tanımlaması}

İnvazif AGS hastalığı tanımı, Dünya Sağlık Örgütü 2005 kriterleri dikkate alınarak; steril vücut bölgelerinden (kan, beyin omurilik SIVISI, eklem SIVISI, plevra SIVISI, periton SIVISI, perikard SIVISI) AGS izolasyonunun yapılması olarak kabul edildi. Streptokokal toksik şok sendromu (STSS) tanısı için "Streptokok Enfeksiyonları Çalışma Grubu"nun tanımı kullanıldı ve doku kültüründen izole edilen (Nekrotizan fasiit veya STSS varlığı) AGS'ler, invazif etken olarak değerlendirildi ${ }^{12}$.

Bakterilerin tanımlaması, beta-hemolitik koloni morfolojisi, Gram boyama özellikleri, katalaz, basitrasin duyarlılık, pyrolidonyl-arilamidaz ve serogrup testleriyle yapıldı. Tüm bakteriler öncelikle katılımcı merkezlerin rutin uygulamaları ile tanımlandı, daha sonra Maltepe Üniversitesi Tıp Fakültesi Tıbbi Mikrobiyoloji Laboratuvarında referans yöntemlerle doğrulandı ${ }^{13}$. 
Türkiye'de İnvazif Streptokok Enfeksiyonlarının Epidemiyolojisi,

Klinik ve Mikrobiyolojik Özellikleri, 2010-2011

\section{Serotiplendirme}

Serotiplendirme opasite faktörü (OF) ve $T$ proteinlerinin araştırılması ile yapıldı ${ }^{8}$. Serum OF araştırması, mikroplak yöntemi ve spektrofotometrik okuma ile ve insan serumu kullanılarak gerçekleştirildi. OF kaynağı olarak kökenlere ait kültür süpernatanları veya $\mathrm{HCl}$ ekstreleri kullanıldı ${ }^{14}$. T-protein aglütinasyonu için, Todd-Hewitt besiyerinde homojen streptokok süspansiyonları hazırlandı. Spontan aglütinasyonu önlemek için süspansiyonlara tripsin eklendi. Bu amaçla, süspansiyona 4 damla domuz pankreas özütü ve 1 damla fenol-kırmızısı pH indikatörü olarak ilave edilerek karıştırıldı. Süspansiyonun pH'sı $\mathrm{NaOH}$ ile mor renk elde edilmesiyle ayarlandı ve 1 saat boyunca $37^{\circ} \mathrm{C}^{\prime}$ de inkübe edildi. Aglütinasyon reaksiyonu, bu süspansiyondan ve ticari olarak sağlanan antiserumlardan (Denka Seiken Co, Japonya) temiz bir lam üzerine Pasteur pipeti ile eşit miktarda konularak araştırıldı.

\section{Genotiplendirme}

İzolatlardan lizatın hazırlanması, emm geni tespiti ve dizilemesi, CDC tarafından önerilen protokole göre aynen uygulandı ${ }^{15}$.

\section{İstatistiksel Analiz}

Olguların demografik verileri SPSS 17 programında frekans analiziyle değerlendirildi. Nominal değerler için ki-kare testi kullanıldı. Yaş, cinsiyet, mevcut klinik veya risk faktörü bilinen olgularda ise regresyon analizi yapıldı.

\section{BULGULAR}

Haziran 2010 ile Haziran 2011 yılları arasında Türkiye'nin 12 bölgesinden 46 merkezde çalışan 15 araştırmacı invazif streptokok enfeksiyonu olan hastalardan izole ettikleri toplam 73 beta-hemolitik streptokok kökenini referans laboratuvarına göndermiştir. Referans laboratuvarda, 65 izolatın AGS olduğu doğrulanmış, diğer 8 suşun ise farklı gruplardan (G, C, B ve F) olduğu tespit edilmiştir.

Olgu sayıları arasında belirgin bölgesel farklılıklar izlenmiş; bölgelere göre izole edilen AGS suş sayıları Tablo I'de gösterilmiştir. En yüksek izolasyon oranı (19/65, \%29) dokuzuncu bölgede (Doğu Karadeniz) saptanmış olup, bu bölge aynı zamanda Türkiye'nin az yoğun nüfuslu bölgesidir. İnvazif AGS izolasyon dağılımı incelendiğinde, izolatların çoğunun, ülkemizin kuzey ve orta bölgelerinden bildirildiği izlenmiştir (Tablo I).

İnvazif AGS enfeksiyonu tanısı konulan hastaların 33'ü kadın, 32'si erkek olup, yaş aralığı 0-89 yıl arasında değişmektedir. Hastaların cinsiyet ve yaş ortalamaları (kadın ve erkek hastalar için sırasıyla 27.5 ve 41.4 yıl) arasında istatistiksel olarak anlamlı bir fark bulunmamıştır ( $p>0.01$ ). AGS suşlarının 18'i yumuşak doku, 10'u apse, 8'i steril vücut SIVISı ve 7'si kan örneklerinden izole edilmiştir. İzolat gönderen merkezler, örnek tipi, hastaların demografik özellikleri, AGS serotip ve emm tipleri Tablo II'de verilmiştir. 


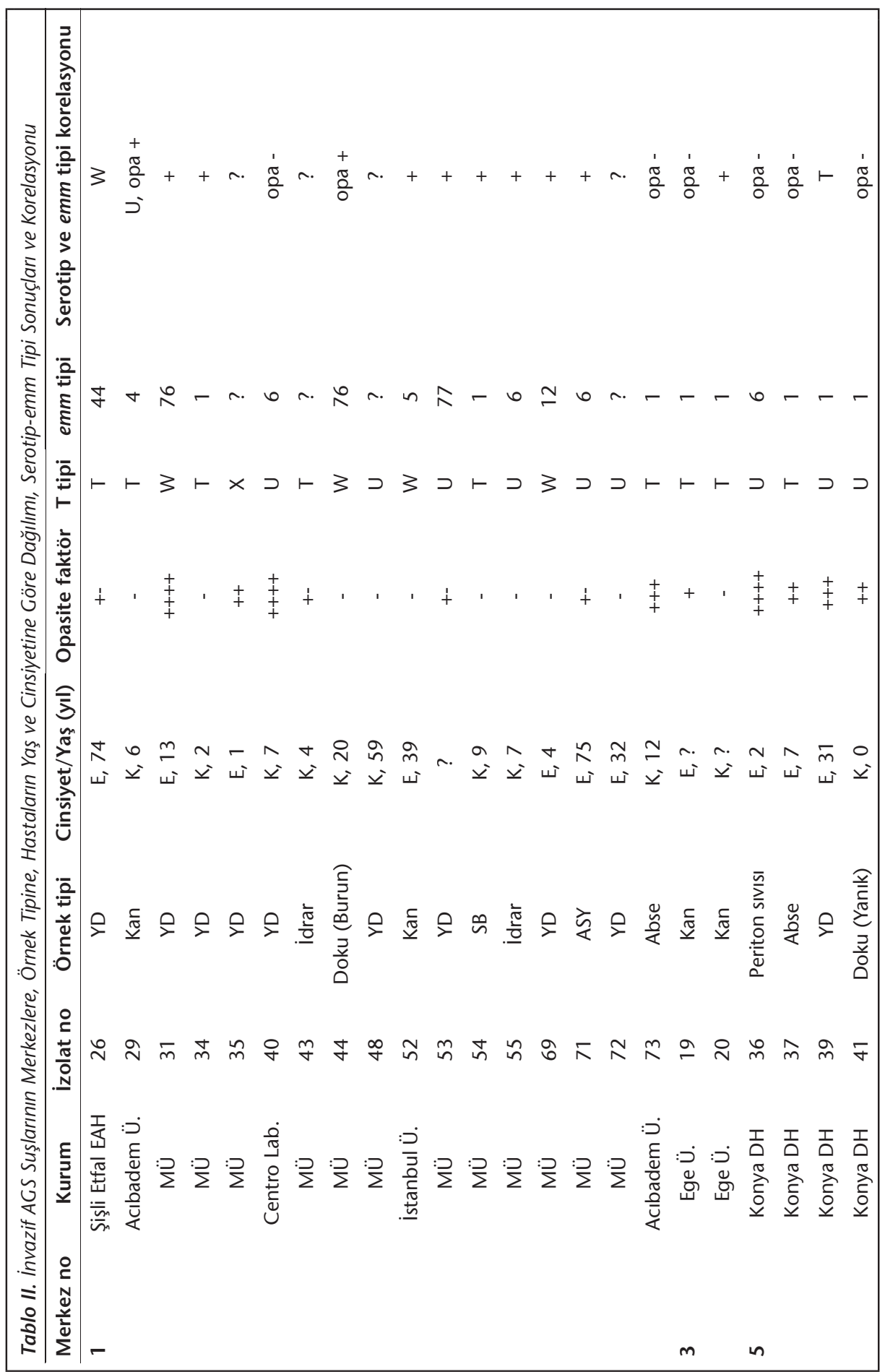




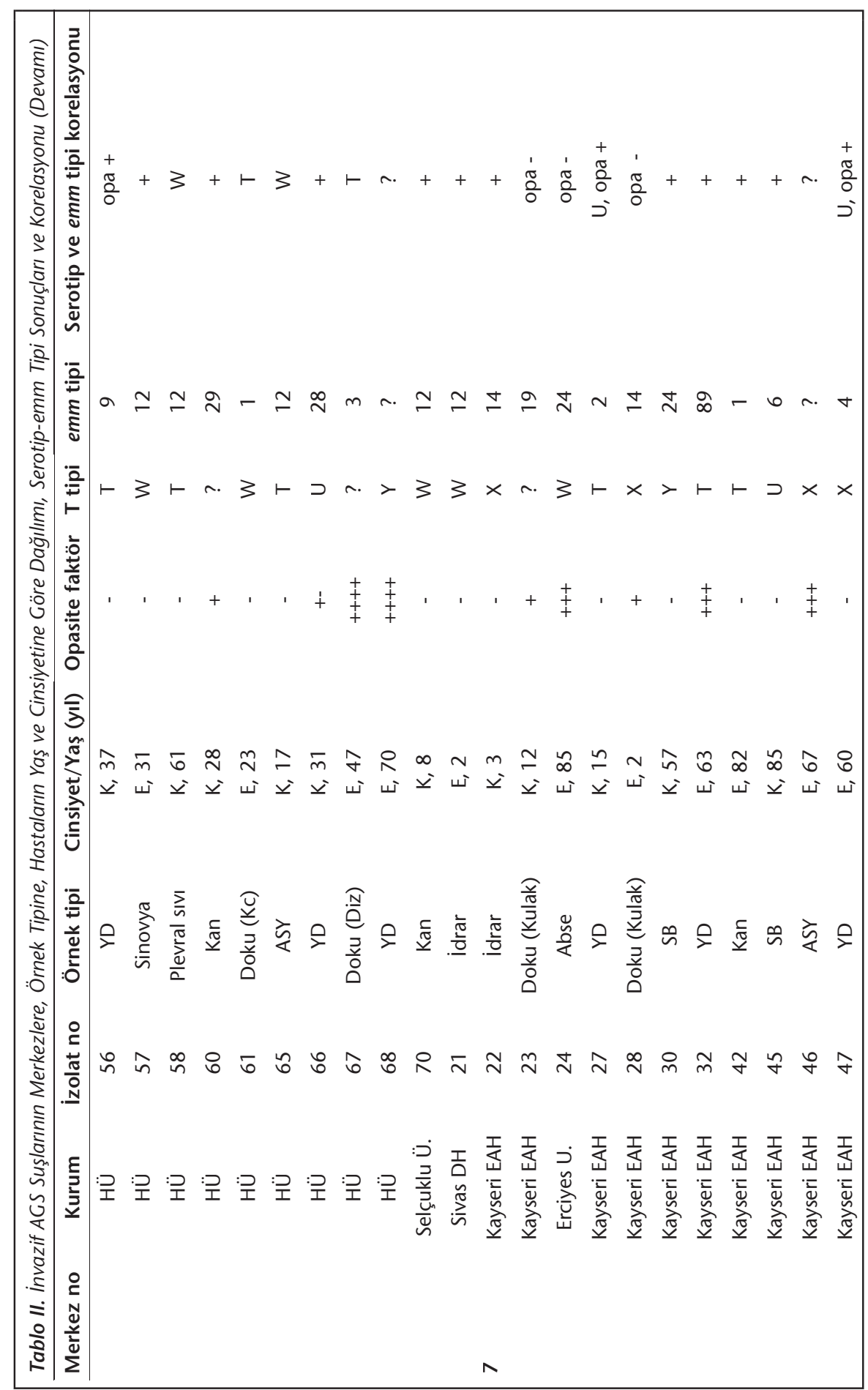




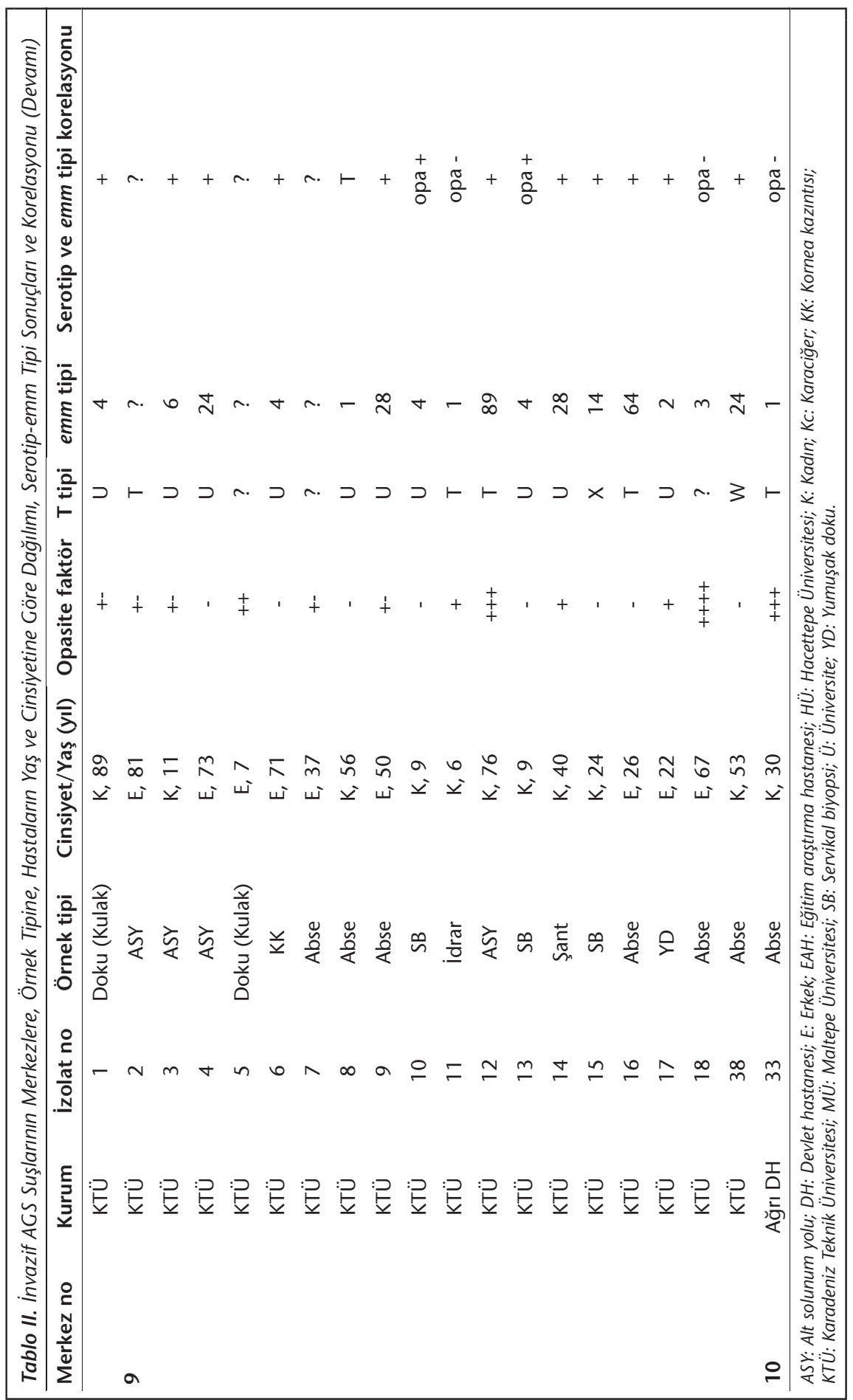


Çalışmamızda, 65 AGS suşunun 36 (\%55)'sının OF pozitif olduğu belirlenmiştir. İzolatlarda en fazla bulunan T proteininin poligrup $T(n=19)$ ve poligrup $U(n=14)$ olduğu, bunları $B(n=5), X(n=3)$ ve $Y(n=2)$ gruplarının izlediği saptanmış; 22 suşun T proteinleri tam olarak tespit edilememiştir. Genotiplendirme sonuçları incelendiğinde, izolatların 17 farklı emm tipine sahip olduğu saptanmıştır. En sık saptanan emm tipleri; emm1 $(n=13)$, emm4 $(n=6)$, emm6 $(n=6)$, emm12 $(n=6)$, emm $24(n=4)$, emm14 $(n=$ 3) ve emm28 ( $\mathrm{n}=3$ ) olmuş, ancak 9 suş dizileme ile de tiplendirilememiştir. Emm tipleri ile OF/T protein serotipleme sonuçları arasındaki korelasyon \%58 olarak bulunmuştur (Tablo II). Yapılan değerlendirmede, aşının invazif kökenlerimize ait emm tiplerinin \%70.5'ini kapsadığı belirlenmiştir (Şekil 1).

\section{TARTIŞMA}

Bu çalışma, invazif A grubu streptokok (AGS) enfeksiyonlarılla ilgili olarak Türkiye'de yapılan ilk toplum kökenli sürveyans çalışmasıdır. Türkiye'de, invazif AGS hastalıklarının, $A B D$, Kanada ve Avrupa ülkeleri ile karşılaştırıldığında düşük endemisiteye sahip olduğu anlaşılmıştır. ABD, Kanada, Danimarka ve Hollanda'da yapılan topluma dayalı sürveyans

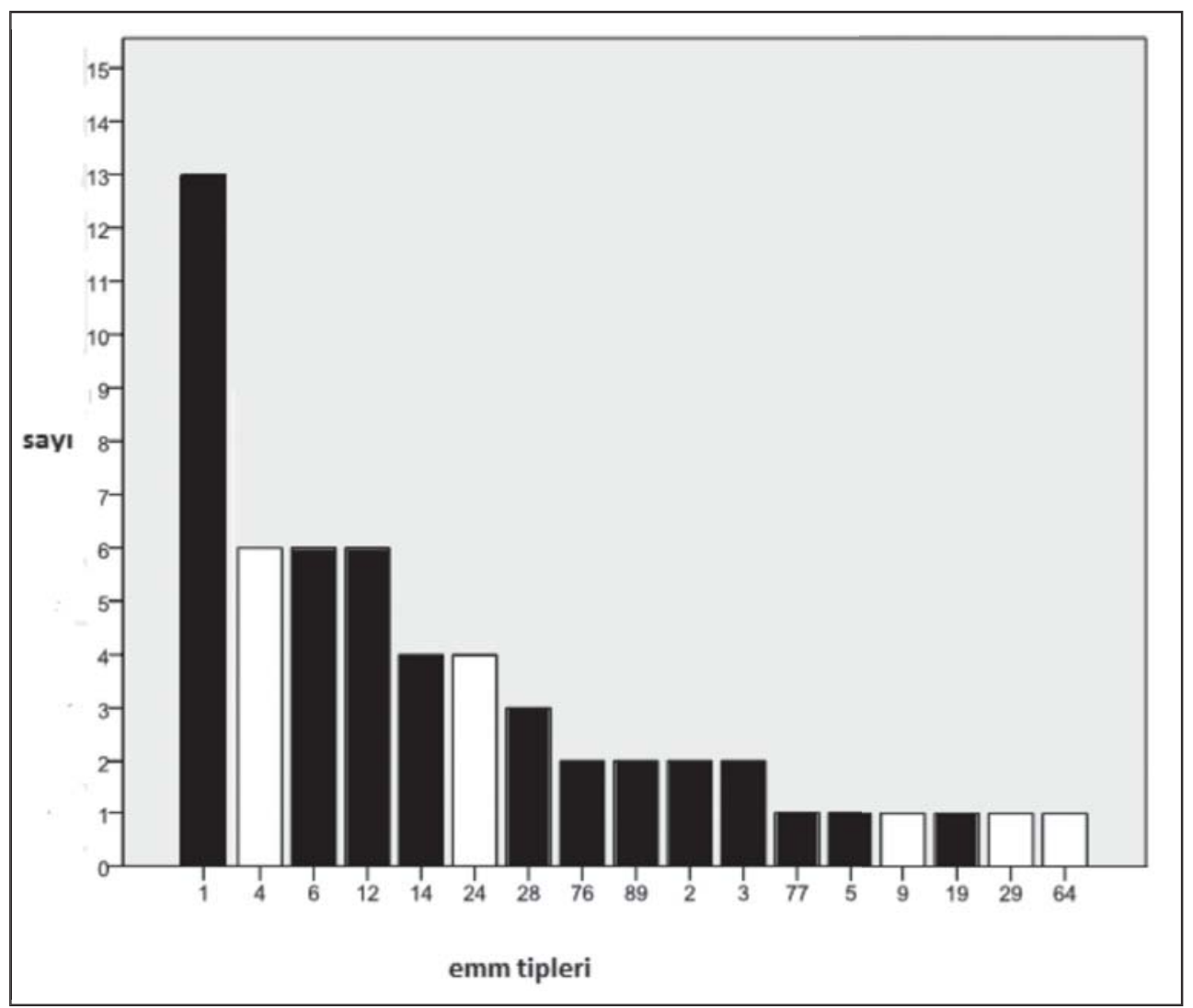

Şekil 1. Incelenen AGS'ların emm tiplerinin dağılımı $(n=65)$ 
çalışmalarında, yılda 100.000 kişide 1.5-5 olgu arasında değiş̧en oranlar bildirilmiş$\mathrm{tir}^{5,9,16,17}$. ABD'de,1998-2003 yıllarını kapsayan topluma dayalı aktif sürveyans çalışması, özellikle 65 yaşın üzerindeki kişilerin invazif AGS enfeksiyonuna yakalanma oranının daha yüksek olduğunu göstermiştir ${ }^{18}$. 1987-1991 yılları arasında Kanada'da yapılan beş yıllık epidemiyolojik çalışmada $^{19}$, en sık görülen serotiplerin M1 ve M12 olduğu belirlenmiş; yine Kanada'da yapılan bir yıllık prospektif sürveyans araştırmasında ${ }^{18}$ da M1 ve M12'ye ek olarak sıklık sırasıyla M4, M28 ve M3 serotiplerinin de saptandığı ve özellikle serotip M1'in SpeA toksin genleri açısından pozitif olduğu rapor edilmiştir. Bu araştırıcılar, 19952001 yılları için Kanada'da invazif hastalık insidansını 2.4/100.000 olarak hesaplamış, $M 1$ ve M3 serotiplerinin olguların 1/3'ünden sorumlu olduğunu vurgulamışlardır ${ }^{16}$. Ingiltere'de 1994 yılında yapılan bir çalışmada ise, beş hastanın kan ve eklem sıvısı örneklerinden izole edilen invazif AGS suşlarınında dört farklı emm tipi (emm1 \{2\}, emm3, emm5) tespit edilmiştir ${ }^{20}$.

Almanya'da yapılan laboratuvara dayalı aktif sürveyans çalışmasında, invazif AGS izolatları arasında en yaygın tiplerin emm1, emm28 ve emm3 olduğu belirlenmiş; bu çalışmada ileri yaş, solunum yolu hastalığı ve şok bulgularının mortaliteyi artırdığı sonucuna varılmıştır ${ }^{21}$. Ekelund ve arkadaşları ${ }^{22}$, Danimarka'da 1999-2002 yılları arasındaki verileri değerlendirmişler; invazif serotip dağılımının yıllara göre önemli ölçüde değiştiğini ve SpeA toksin genlerinin emm1 genotiplerinde anlamlı derecede yüksek olduğunu bildirmişlerdir. Avrupa'da 16 ülkenin katılımıyla gerçekleşen, invazif streptokok enfeksiyonlarının epidemiyolojik ve mikrobiyolojik özelliklerinin araştırıldığı StrepEURO Projesi sonuçlarına göre; 2001-2004 yılları arasında yaygın olan serotiplerin, Danimarka'da M1 ve M28, Yunanistan'da M1 ve M12, İsveç'te ise M89, M81, M28 ve M1 olduğu tespit edilmiştir ${ }^{13}$. Steer ve arkadaşlarının ${ }^{23}$, emm tiplerinin global dağılımını belirlemek ve aşıların içeriğine katkıda bulunmak amacıyla, 38.081 AGS kökeniyle ilgili 102 çalışmayı değerlendirdikleri analizde, gelişmiş ülkelerin hemen hepsinde çok sayıda verinin olduğu, ancak az gelişmiş ülkelerdeki verilerin dikkate değer ölçüde az olduğu vurgulanmıştır. CDC tarafından yayınlanan verilerle karşılaştırıldığında, bizim çalışmamızda saptanan emm tiplerinin, en çok Avrupa ülkelerinin verilerine benzerlik gösterdiği izlenmektedir $5,9,18,20,23$.

Finlandiya'da 1995 yılında başlayan ve 10 yıllık süreyi kapsayan çalışmanın sonuçlarına göre, invazif AGS enfeksiyonları sıklığının her yıl giderek artış gösterdiği, 1995 yılında 1.1/100.000 olgu olan insidansın, 2004 yılında 2.5/100.000'e ulaştığı vurgulanmıştı ${ }^{24}$. Konu ile ilgili tüm çalışmaların ilginç bir ortak özelliği, 100'den fazla emm tipi arasında sadece beş ya da altı tanesinin invazif AGS hastalıklarının yaklaşık yarısından sorumlu olduğunun saptanmasıdır kökenlerin \%60'ını yedi çeşit emm tipi oluşturmaktadır. AGS serotipleri ile emm tipleri arasında tam (\%100) bir korelasyon olmaması nedeniyle, AGS suşları yaygın olarak M proteinini kodlayan emm gen bölgesi dizisinin değişimleri bazında sınıflandırılmaktadır ${ }^{8}$. Çalışmamızda da M proteinini kodlayan emm tiplerinin heterojen olduğu görülmüştür 
(Tablo II). Ülkemizde Arslan ve arkadaşlarının²5, 35 AGS izolatı ile yaptıkları çalışmada, 15 farklı emm genotipi saptanmış, en sık saptanan tip, bizim çalışmamızda olduğu gibi emm1 olarak bulunmuş ve 26 valanlı aşının, bu tiplerin \%60'ını kapsadığı rapor edilmiştir. Bizim çalışmamızda, aşının kapsama oranı \%70.5 olarak belirlenmiş, bu yüksek oranın sadece invazif suşların çalışmaya dahil edilmesinden kaynaklandığı düşünülmüştür. Nitekim Arslan ve arkadaşları ${ }^{25}$, kan kültüründen izole edilen invazif suşların hepsinin aşı kapsamında olduğunu ifade etmişlerdir.

Çalışmamızda, invazif AGS enfeksiyonlarının sıklığı belirgin bölgesel farklılıklar göstermiş; suşların çoğunun, ülkemizin kuzey ve orta bölgelerinde yer alan merkezlerde izole edildiği dikkati çekmiştir (Tablo I). Bu bölgeler güney bölgeleri ile karşılaştırıldığında, daha serin ve nemli iklime sahiptir. O'Loughlin ve arkadaşlarının ${ }^{3}$ yaptığı epidemiyolojik çalışmada, ABD'nin bazı eyaletlerinde (Colorado, Maryland) invazif AGS daha sık görülmesine rağmen mevsimsel bir bağlantı kurulmamıştır.

Sonuç olarak, bu çalışma ile Türkiye'de invazif AGS enfeksiyonlarının epidemiyolojik ve mikrobiyolojik özellikleriyle ilgili ilk veriler elde edilmiştir. Çalışmamızın sonuçları, bu tip enfeksiyonların ülkemizde yüksek sıklıkta görülmediğini, 26 değerli ASG aşısının aşı programına dahil edilmesinin ülkemiz için acil halk sağlığı sorunu olmadığını ve eğer kullanılacaksa aşıya emm4 ve emm24 tiplerinin de eklenmesi gerektiğini ortaya koymuştur. Ek olarak, bu enfeksiyonların epidemiyolojik ve mikrobiyolojik özellikleri zamanla değişebileceğinden, invazif streptokok hastalıklarının tanısı ve uygun önlemlerin alınabilmesi için epidemiyolojik çalışmaların belirli dönemlerde tekrarlanmasının uygun bir yaklaşım olacağı kanısına varılmıştır.

\section{TEŞEKKÜR}

Bu çalışmanın planlanmasında katkı sağlayan Prof. Haydar Sur ve Prof. Dr. Hasan Boynukara'ya teşekkür ederiz.

\section{KAYNAKLAR}

1. Stevens DL. Invasive group A streptococcal disease. Infect Agents Dis 1996; 5(3): 157-66.

2. Hoge CW, Schwartz B, Talkington DF, Breiman RF, MacNeill EM, Englender SJ. The changing epidemiology of invasive group A streptococcal infections and the emergence of streptococcal toxic shock-like syndrome. A retrospective population-based study. JAMA 1993; 269(3): 384-9.

3. O'Loughlin RE, Roberson A, Cieslak PR, et al. The epidemiology of invasive group A streptococcal infection and potential vaccine implications: United States, 2000-2004. Clin Infect Dis 2007; 45(7): 853-62.

4. O'Grady KA, Kelpie L, Andrews RM, et al. The epidemiology of invasive group A streptococcal disease in Victoria, Australia. Med J Aust 2007; 186(11): 565-9.

5. O'Brien KL, Beall B, Barrett NL, et al. Epidemiology of invasive group A streptococcus disease in the United States, 1995-1999. Clin Infect Dis 2002; 35(3): 268-76.

6. Courtney HS, Hasty DL, Dale JB. Anti-phagocytic mechanisms of Streptococcus pyogenes: binding of fibrinogen to M-related protein. Mol Microbiol 2006; 59(3): 936-47. 
7. Faclam RF, Martin DR, Lovgren M, et al. Extension of the Lancefield classification for group A streptococci by addition of 22 new M protein gene sequence types from clinical isolates: emm103 to emm124. Clin Infect Dis 2002; 34(1): 28-38.

8. Johnson DR, Kaplan EL, VanGheem A, Facklam RR, Beall B. Characterization of group A streptococci (Streptococcus pyogenes): correlation of M-protein and emm-gene type with T-protein agglutination pattern and serum opacity factor. J Med Microbiol 2006; 55(Pt 2): 157-64.

9. Luca-Harari B, Darenberg J, Neal S, et al. Clinical and microbiological characteristics of severe Streptococcus pyogenes disease in Europe. J Clin Microbiol 2009; 47(4): 1155-1165.

10. Bayramoğlu G, Topkaya AE, Balıkcı A, Aydın F. Serotypes and antimicrobial susceptibilities of invasive group A streptococci identified in eastern Black Sea region of Turkey. Mikrobiyol Bul 2011; 45(3): 446-53.

11. Topkaya AE, Yildirim T, Arsan S. Isolation ratio and T- serotyping of group A streptococci from pediatric upper respiratory tract infections in Turkey. Anadolu Kardiyol Derg 2005; 5(4): 302-4.

12. Breiman RF, Davis JP, Facklam RR, et al. Defining the group A streptococcal toxic shock syndrome. Rationale and consensus definition. The Working Group on Severe Streptococcal Infections. JAMA 1993; 269(3): 390-1.

13. Centers for Disease Control and Prevention. Streptococcus pyogenes emm sequence database. Identification of other Streptococcus Species: Streptococcus general methods. Available at: http://www.cdc.gov/ncidod/ biotech/strep/strep-doc/index.htm

14. Rehder CD, Johnson DR, Kaplan EL. Comparison of methods for obtaining serum opacity factor from group A streptococci. J Clin Microbiol 1995; 33(11): 2963-7.

15. Centers for Disease Control and Prevention. Streptococcus pyogenes emm sequence database. Protocol for emm typing. Available at: http://www.cdc.gov/ncidod/biotech/strep/protocol_emm-type.htm

16. Hollm-Delgado MG, Allard R, Pilon PA. Invasive group A streptococcal infections, clinical manifestations and their predictors, Montreal, 1995-2001. Emerg Infect Dis 2005; 11(1): 77-82.

17. Davies HD, McGeer A, Schwartz B, et al. Invasive group A streptococcal infections in Ontario, Canada. Ontario Group A Streptococcal Study Group. N Engl J Med 1996; 335(8): 547-54.

18. Thigpen MC, Richards CL Jr, Lynfield R, et al; Active Bacterial Core Surveillance/Emerging Infections Program Network. Invasive group A streptococcal infection in older adults in long-term care facilities and the community, United States, 1998-2003. Emerg Infect Dis 2007; 13(12): 1852-9.

19. Demers $B$, Simor AE, Vellend $H$, et al. Severe invasive group A streptococcal infections in Ontario, Canada: 1987-1991. Clin Infect Dis 1993; 16(6): 792-800.

20. Centers for Disease Control and Prevention (CDC). Invasive group A streptococcal infections--United Kingdom, 1994. MMWR Morb Mortal Wkly Rep 1994; 43(21): 401-2.

21. Wahl RU, Lütticken R, Stanzel S, van der Linden M, Reinert RR. Epidemiology of invasive Streptococcus pyogenes infections in Germany, 1996-2002: results from a voluntary laboratory surveillance system. Clin Microbiol Infect 2007; 13(12): 1173-8.

22. Ekelund K, Skinhøj P, Madsen J, Konradsen HB. Reemergence of emm1 and a changed superantigen profile for group A streptococci causing invasive infections: results from a nationwide study. J Clin Microbiol 2005; 43(4): 1789-96.

23. Steer AC, Batzloff MR, Mulholland K, Carapetis JR. Group A streptococcal vaccines: facts versus fantasy. Curr Opin Infect Dis 2009; 22(6): 544-52.

24. Siljander T, Toropainen M, Muotiala A, Hoe NP, Musser JM, Vuopio-Varkila J. Emm typing of invasive T28 group A streptococci, 1995-2004, Finland. J Med Microbiol 2006; 55(Pt 12): 1701-6.

25. Arslan U, Oryaşın E, Eskin Z, et al. Distribution of emm genotypes and antibiotic susceptibility of Streptococcus pyogenes strains: analogy with the vaccine in development. Mikrobiyol Bul 2013; 47(2): 318-23. 